\title{
DISPERSION CHARACTERISTICS OF METAMATERIAL HOLLOW-CORE CYLINDRICAL WAVEGUIDES *
}

\author{
L. Nickelson, T. Gric, and S. Ašmontas \\ Semiconductor Physics Institute, A. Goštauto 11, LT-01108 Vilnius, Lithuania \\ E-mail: nick@pfi.lt
}

Received 12 June 2007; revised 23 July 2007

\begin{abstract}
The work deals with the study of metamaterial hollow-core cylindrical (MHC) waveguides. In the article the solution of Maxwell's equations to analyse a MHC waveguide is presented. A dispersion equation was obtained in the form of a determinant. We created the computer algorithm in MATLAB language to investigate the dispersion properties of the MHC waveguide. The MHC waveguide was studied in the frequency range from 75 to $115 \mathrm{GHz}$ with different waveguide parameters (radius, azimuthal index). We have analysed the dependences of the MHC waveguide main and higher order modes' dispersion characteristics on a waveguide radius and an azimuthal index.
\end{abstract}

Keywords: metamaterial, hollow cylindrical waveguide, Maxwell's equations, dispersion equation, computer algorithm, MATLAB, numerical calculations, dispersion characteristics

PACS: 42.81.Qb

\section{Introduction}

Metamaterials (left-handed materials) are the artificial structures which consist of the arrays of periodically repeated elements, i.e. unit cells. Metamaterials have such name because of their ability to interact with electromagnetic waves in the way the natural materials cannot. The functional electromagnetic response of metamaterials arises from the ability to rectify the resonant electric and / or magnetic response through design of the sub-wavelength resonator elements [1].

Recently, there has been a rapid growth of interest in metamaterials. For example, Ruppin demonstrated the existence of a surface polariton mode at the interface between metamaterial medium and dielectric material $[2,3]$.

One possible application area for MHC waveguides is in telecommunications. MHC waveguides could conceivably demonstrate lower, or even far lower, optical attenuation than conventional fibres, which are limited by the optical properties of their solid cores [4]. Another application area of the MHC waveguides is the field of laser delivery. With their greatly reduced nonlinearity [5] and increased damage thresholds [6], and with dispersion characteristics very different to conven-

\footnotetext{
* The report presented at the 37th Lithuanian National Physics Conference, 11-13 June 2007, Vilnius, Lithuania.
}

tional fibres, this application area looks like a significant opportunity.

Metamaterial waveguides are very promising in terms of application in optical communication. Metamaterial waveguides have been suggested and demonstrated as optical waveguides, filters, polarizers and splitters, couplers, optical fibres, delay lines and wavelength demultiplexors, high-energy accelerators [7].

In this article we present dispersion characteristics of electromagnetic main and higher order modes in the MHC waveguides in the $75-115 \mathrm{GHz}$ frequency range.

The structure of the article is as follows. The second section introduces dispersion equation of the MHC waveguide. The third section presents main principles of creation of the computer algorithm in MATLAB language. In this part testing of the made algorithm is also presented. Numerical computations are described in the Section 4 followed by the Conclusions section.

\section{The dispersion equation of the MHC waveguide}

A solution of Maxwell's equations to analyse MHC waveguides is presented in this part.

The method we have used to solve our waveguide problem is based on two approaches. The first is the coupled mode method and the second is the partial area method. 


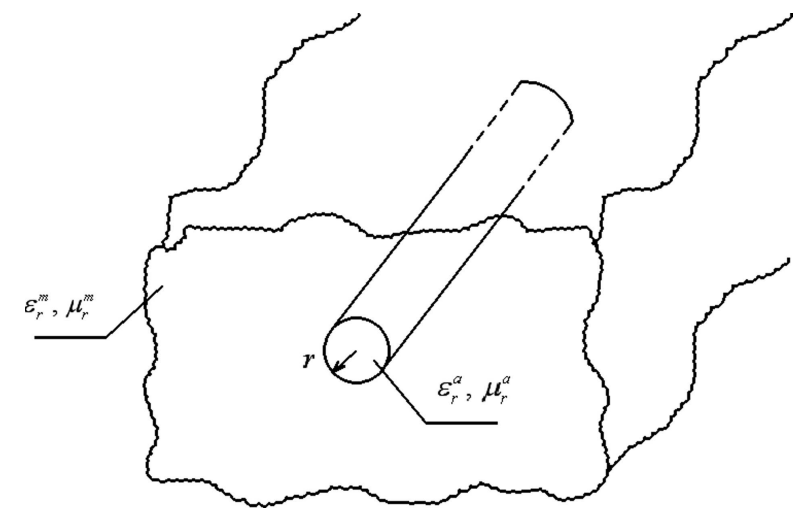

Fig. 1. MHC waveguide model.

The form of longitudinal components of electric field $E_{z}^{\mathrm{a}}$ and magnetic field $H_{z}^{\mathrm{a}}$ that satisfies Maxwell's equations in the air medium is as follows:

$$
\begin{aligned}
& E_{z}^{\mathrm{a}}=A_{1} J_{m}\left(k_{\perp}^{\mathrm{a}} r\right) \exp (\mathrm{i} m \varphi), \\
& H_{z}^{\mathrm{a}}=B_{1} J_{m}\left(k_{\perp}^{\mathrm{a}} r\right) \exp (\mathrm{i} m \varphi),
\end{aligned}
$$

where $A_{1}, B_{1}$ are unknown arbitrary amplitudes, $J_{m}$ is the Bessel function, $k_{\perp}^{\mathrm{a}}$ is the transverse propagation constant for the air medium, $r$ is the radius of the MHC waveguide, $m$ is the azimuthal index characterizing angle variations of the field, $\varphi$ is the azimuthal coordinate.

The representation of longitudinal components of electric and magnetic fields that satisfies Maxwell's equations in the metamaterial infinite medium is as follows:

$$
\begin{aligned}
& E_{z}^{\mathrm{m}}=A_{2} H_{m}\left(k_{\perp}^{\mathrm{m}} r\right) \exp (\mathrm{i} m \varphi), \\
& H_{z}^{\mathrm{m}}=B_{2} H_{m}\left(k_{\perp}^{\mathrm{m}} r\right) \exp (\mathrm{i} m \varphi),
\end{aligned}
$$

where $H_{m}$ is the Hankel function of the second kind.

We have expressed azimuthal components $E_{\varphi}, H_{\varphi}$ through longitudinal components $E_{z}, H_{z}$ of the electromagnetic field and equated tangential components with each other. The satisfied boundary conditions are as follows:

$$
\begin{aligned}
E_{z}^{\mathrm{a}} & =E_{z}^{\mathrm{m}}, \\
H_{z}^{\mathrm{a}} & =H_{z}^{\mathrm{m}}, \\
E_{\varphi}^{\mathrm{a}} & =E_{\varphi}^{\mathrm{m}}, \\
H_{\varphi}^{\mathrm{a}} & =H_{\varphi}^{\mathrm{m}} .
\end{aligned}
$$

The dispersion equation of the MHC waveguide is

$$
\Delta=\eta^{2} \chi^{2} h^{2} m^{2}\left(\frac{1}{\left(k_{\perp}^{\mathrm{m}}\right)^{2} r}-\frac{1}{\left(k_{\perp}^{\mathrm{a}}\right)^{2} r}\right)^{2}+
$$

$$
\begin{aligned}
& +\eta \eta^{\prime} \chi \chi^{\prime} \frac{k^{2}}{k_{\perp}^{\mathrm{a}} k_{\perp}^{\mathrm{m}}}\left(\varepsilon_{r}^{\mathrm{m}} \mu_{r}^{\mathrm{a}}+\varepsilon_{r}^{\mathrm{a}} \mu_{r}^{\mathrm{m}}\right)- \\
& -\eta^{2}\left(\chi^{\prime}\right)^{2} \frac{\varepsilon_{r}^{\mathrm{m}} \mu_{r}^{\mathrm{m}} k^{2}}{\left(k_{\perp}^{\mathrm{m}}\right)^{2}}-\left(\eta^{\prime}\right)^{2} \chi^{2} \frac{\varepsilon_{r}^{\mathrm{a}} \mu_{r}^{\mathrm{a}} k^{2}}{\left(k_{\perp}^{\mathrm{a}}\right)^{2}},
\end{aligned}
$$

where $\eta=J_{m}\left(k_{\perp}^{\mathrm{a}} r\right), \chi=H_{m}\left(k_{\perp}^{\mathrm{m}} r\right), \eta^{\prime}$, and $\chi^{\prime}$ are derivatives of quantities $\eta$ and $\chi$ correspondingly, $\varepsilon_{r}^{\mathrm{m}}$ and $\varepsilon_{r}^{\mathrm{a}}$ are the permittivity of the metamaterial and the free space correspondingly, $\mu_{r}^{\mathrm{m}}$ and $\mu_{r}^{\mathrm{a}}$ are the permeability of the metamaterial and the free space correspondingly. Quantities $k_{\perp}^{\mathrm{m}}$ and $k_{\perp}^{\mathrm{a}}$ are related with the longitudinal propagation constant and material constants (the permittivity and permeability of the metamaterial) as follows:

$$
\begin{aligned}
& k_{\perp}^{\mathrm{m}}=\sqrt{k^{2} \varepsilon_{r}^{\mathrm{m}} \mu_{r}^{\mathrm{m}}-h^{2}}, \\
& k_{\perp}^{\mathrm{a}}=\sqrt{k^{2} \varepsilon_{r}^{\mathrm{a}} \mu_{r}^{\mathrm{a}}-h^{2}},
\end{aligned}
$$

where $k=\omega / c$ is the wave number in a vacuum, $h$ is the longitudinal propagation constant.

We obtained the dispersion equations in the form of a determinant and created a MATLAB computer program to investigate the MHC waveguide. The computer algorithm is based upon the dispersion equation (9) above. The system of algebraic equations for the unknown $h$ obtained from the boundary conditions is homogeneous. The condition of solvability was obtained equalling the determinant of the system to zero. Since our dispersion equation cannot be solved analytically, longitudinal propagation constants have been obtained by searching for a root of the dispersion equation.

The program is made in the following way: user can choose waveguide parameters (permittivities and permeabilities of the waveguide media, radius of the waveguide, value of the index $m$ ).

Testing of the program was carried out using the article [8]. In that article the dispersion characteristics of an open cylindrical dielectric rod waveguide are presented.

\section{Numerical results}

In this section we present the numerical results of electrodynamical investigations of the MHC waveguide. We have analysed the dispersion characteristics of the main and higher modes of a MHC waveguide. Metamaterial in this case is represented by the medium which is made of three layers. There are three strips in 


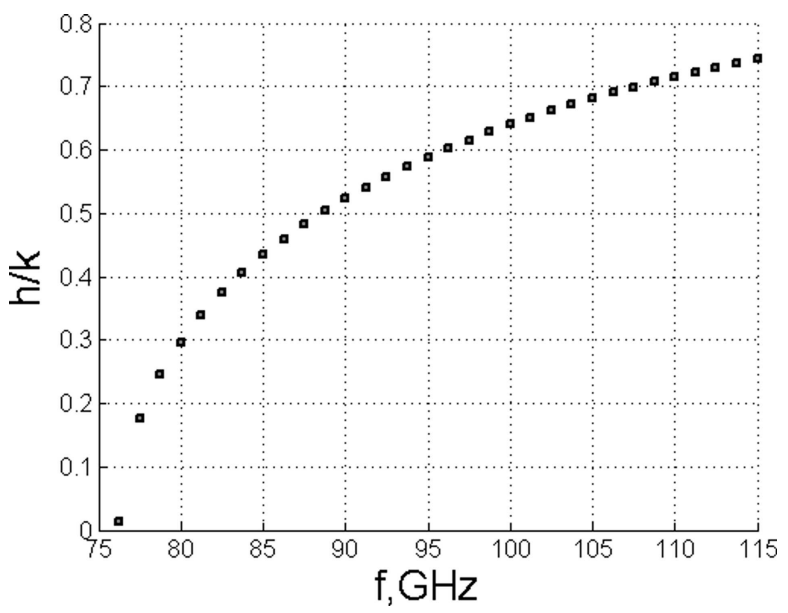

Fig. 2. Dispersion characteristics of the MHC waveguide when $m=1, r=1 \mathrm{~mm}$.

the first and the third layers, and two split-rings in the second layer [9].

Metamaterial parameters' dependence on frequency in the $75-115 \mathrm{GHz}$ frequency range is presented in the article [9]. According to this metamaterial parameters' dependence the MHC waveguide properties have been analysed in the above-mentioned frequency interval.

\subsection{Analysis of the MHC waveguide properties on the waveguide radius $r$}

It is known that the larger the radius of the waveguide, the greater number of modes is transmitted in the waveguide. This statement has been checked by analysing MHC waveguide. Parameters of the analysed metamaterial correspond to the permittivity and permeability dependence on frequency published in [9]. The values of permittivity and permeability of the metamaterial medium that we have used belong to the 75$115 \mathrm{GHz}$ frequency range. These values are given in Table 1.

We have analysed the cases when radius of the waveguide is $1,2,3$, and $8 \mathrm{~mm}$.

In Fig. 2 we see that when the radius $r=1 \mathrm{~mm}$, there is only the main mode in the MHC waveguide. The cutoff frequency of this mode is $76.25 \mathrm{GHz}$. We should note that such waveguide works in one mode regime in the frequency range of $75-115 \mathrm{GHz}$.

In Fig. 3 we see that when $r=2 \mathrm{~mm}$, there are 2 modes in the MHC waveguide. We cannot determine the cutoff frequency of the main mode because it has shifted to the left and does not belong to the $75-115 \mathrm{GHz}$ frequency range. We should notice that the cutoff frequency of the second higher mode is $87.5 \mathrm{GHz}$.
Table 1. Values of the metamaterial permittivity and permeability in the $75-115 \mathrm{GHz}$ frequency range [9].

\begin{tabular}{|c|c|c|}
\hline$f, \mathrm{GHz}$ & $\varepsilon_{r}^{\mathrm{m}}$ & $\mu_{r}^{\mathrm{m}}$ \\
\hline 75 & -41.25 & 1.17 \\
\hline 76.25 & -38.33 & 1.17 \\
\hline 77.5 & -38.33 & 1.25 \\
\hline 78.75 & -35 & 1.17 \\
\hline 80 & -35 & 1.17 \\
\hline 81.25 & -35 & 1.17 \\
\hline 82.5 & -33.75 & 1.17 \\
\hline 83.75 & -32.5 & 1.17 \\
\hline 85 & -31.25 & 1.17 \\
\hline 86.25 & -31.25 & 1.17 \\
\hline 87.5 & -30 & 1.17 \\
\hline 88.75 & -30 & 1.17 \\
\hline 90 & -30 & 1.67 \\
\hline 91.25 & -31.67 & 1.835 \\
\hline 92.5 & -38.33 & 2.5 \\
\hline 93.75 & -30 & 2.33 \\
\hline 95 & -22.5 & 1.34 \\
\hline 96.25 & -16.67 & 1.5 \\
\hline 97.5 & -10 & 1.25 \\
\hline 98.75 & -6.67 & 1 \\
\hline 100 & -6.67 & -1.75 \\
\hline 101.25 & -8.33 & -0.625 \\
\hline 102.5 & -10 & 0 \\
\hline 103.75 & -10 & 0 \\
\hline 105 & -10 & 0.25 \\
\hline 106.25 & -10 & 0.5 \\
\hline 107.5 & -10 & 0.25 \\
\hline 108.75 & -10 & 0.5 \\
\hline 110 & -10 & 0.25 \\
\hline 111.25 & -8.33 & 0.5 \\
\hline 112.5 & -8.33 & 0.5 \\
\hline 113.75 & -8.33 & 0.5 \\
\hline 115 & -10 & 0.5 \\
\hline
\end{tabular}

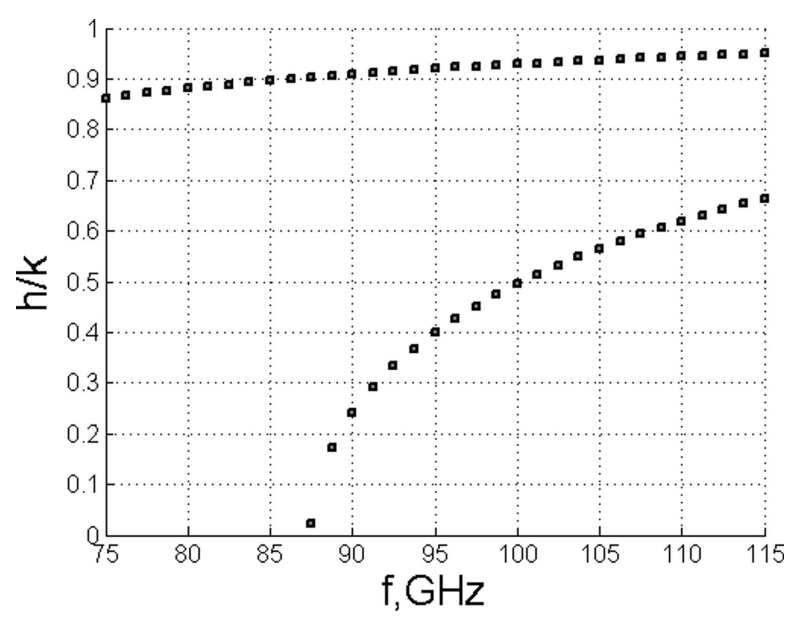

Fig. 3. Dispersion characteristics of the MHC waveguide, $m=1$, $r=2 \mathrm{~mm}$. 


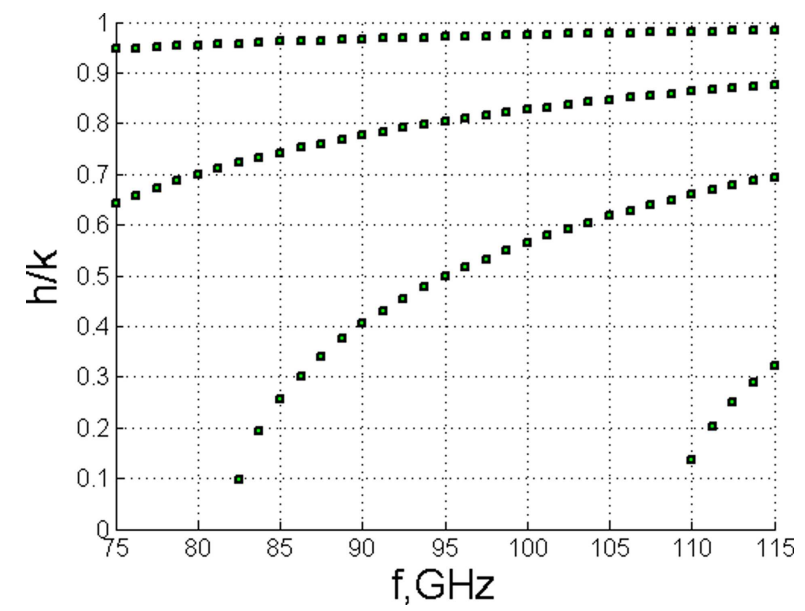

Fig. 4. Dispersion characteristics of the MHC waveguide, $m=1$, $r=3 \mathrm{~mm}$.

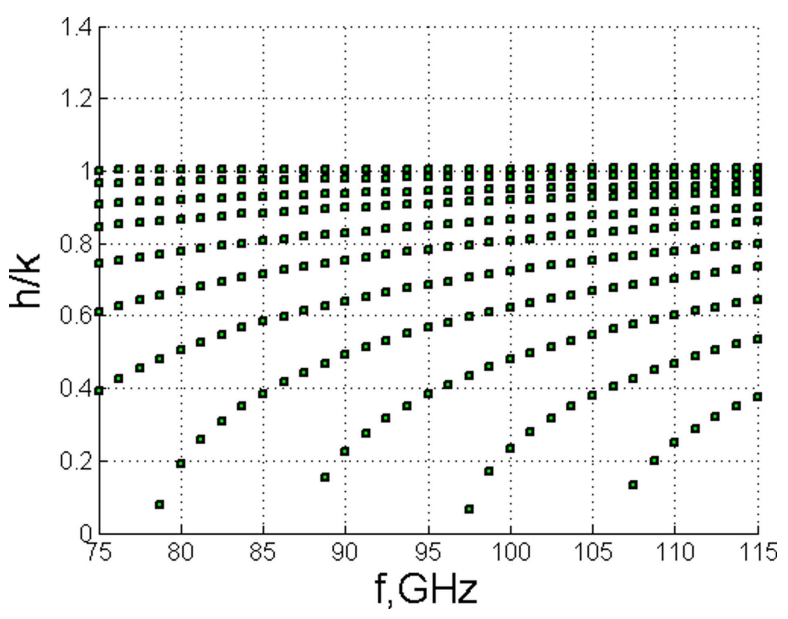

Fig. 5. Dispersion characteristics of the MHC waveguide, $m=1$, $r=8 \mathrm{~mm}$.

In Fig. 4 we see that when $r=3 \mathrm{~mm}$, there are 4 modes in the MHC waveguide. Here we can see that the cutoff frequencies of the main as well as the first higher modes have shifted out of the considered frequency range. We have determined that the cutoff frequencies of the second and the third higher modes are 81.25 and $108.75 \mathrm{GHz}$ correspondingly.

Figure 5 shows dispersion characteristics of the MHC waveguide when the waveguide radius has been strongly enlarged comparing with the waveguides we have analysed before. In Fig. 5 we see that when $r=$ $8 \mathrm{~mm}$, there are 11 modes in the MHC waveguide. We see that the cutoff frequencies of seven higher modes have shifted outside the left limit of the considered frequency range. The cutoff frequencies of seventh, eighth, ninth, tenth higher modes are 78.75, 88.75, 97.5 , and $106.25 \mathrm{GHz}$ respectively.

We can draw the conclusion that the larger radius of the MHC waveguide is, the larger number of hybrid

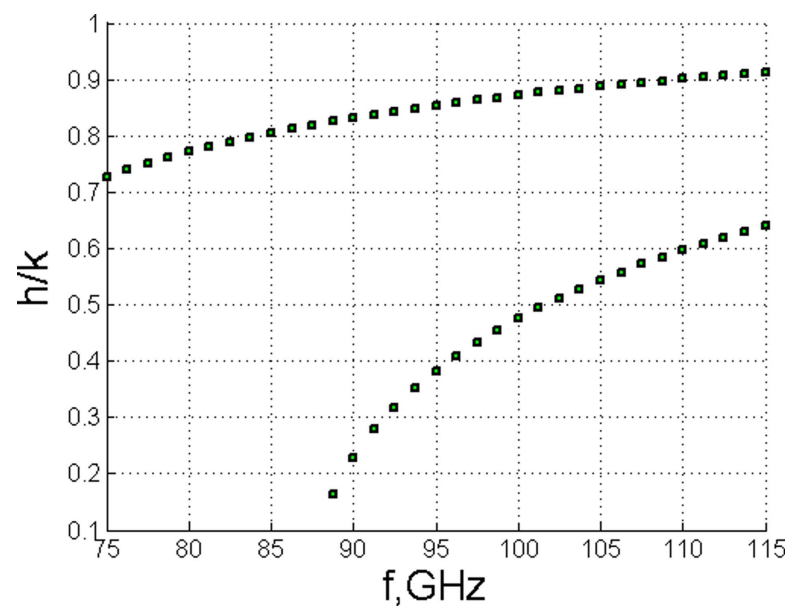

Fig. 6. Dispersion characteristics of the MHC waveguide when $m=0, r=2 \mathrm{~mm}$.

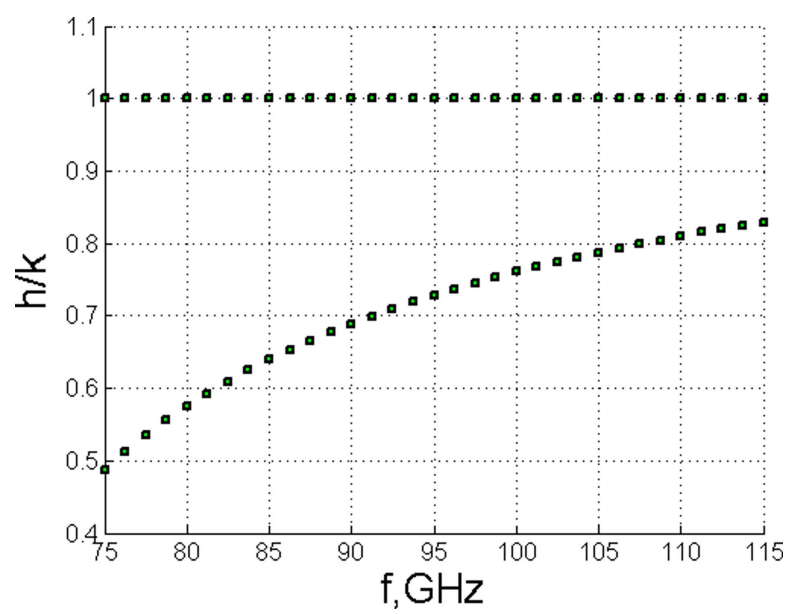

Fig. 7. Dispersion characteristics of the MHC waveguide, $m=2$, $r=2 \mathrm{~mm}$.

$H E_{m n}$ and $E H_{m n}$ modes is propagated in such waveguide.

\subsection{Analysis of the MHC waveguide properties at azimuthal index $m=0$ and 2}

We have analysed the propagation of symmetric modes in the MHC waveguide with the azimuthal in$\operatorname{dex} m=0$ and 2 .

We have analysed the case when $m=0$ and radius $r=2 \mathrm{~mm}$. In this case the axis-symmetric modes propagate in the MHC waveguide.

Comparing Figs. 3 and 6 we can draw a conclusion that when the value of the azimuthal index $m$ decreases, the cutoff frequency $f_{\mathrm{c}}$ of the first higher mode moves to the right $\left(f_{\mathrm{c}}=88.75 \mathrm{GHz}\right)$.

We also have analysed the case when $m=2$ and the radius $r=2 \mathrm{~mm}$. 
Comparing Figs. 3 and 7 we can draw a conclusion that when the value of the azimuthal index $m$ increases, the cutoff frequency of the first higher mode moves to the left. We cannot determine the exact value of the cutoff frequency of this mode because its value is smaller than 75 GHz. From Fig. 7 we can see that when the azimuthal index $m=2$, the main symmetric mode is parallel to the frequency axis. This means that the longitudinal propagation constant is practically independent of the frequency. The MHC waveguide for the mode with indexes $m=2$ and $n=1$ is a nondispersional waveguide structure. The phase speed of this mode is equal to the light speed $\left(c \approx 3 \cdot 10^{8} \mathrm{~m} / \mathrm{s}\right)$.

Comparing Figs. 6 and 7 we can note that the axis-symmetric mode with indices $m=0$ and $n=1$ crosses the ordinate axis in the point with value 0.725 when frequency is $75 \mathrm{GHz}$. The symmetric mode with indices $m=2$ and $n=1$ crosses the ordinate axis in the point with value 1 when frequency is $75 \mathrm{GHz}$. We can draw a conclusion that the greater is the azimuthal index of the symmetric waves, the larger is the $h$ value. Therefore the length of the wave propagated in the MHC waveguide is smaller.

Analysing the dispersion characteristics given in [8] and our dispersion characteristics of the MHC waveguide, we can draw an interesting conclusion: the ratio of $h$ and $k$ values for dielectric rod waveguides $h / k$ is $>1$ [8]. Such waveguides can be used in delay lines. The same ratio for the MHC waveguide is $h / k \leq 1$ (see Figs. 2-7). Therefore the MHC waveguides can be used as high-energy accelerators.

\section{Conclusions}

We have obtained the solution of Maxwell's equations to analyse MHC waveguides. The method we have used to solve waveguide problems is based on two approaches. The first approach is the coupled mode method and the second one is the partial area method.

According to the dispersion equation of the MHC waveguide we have created the computer algorithm with 2D graphical visualization in MATLAB language. This computer algorithm has been tested using the article [8]. We have got dispersion characteristics of the MHC waveguide with different parameters (radius, azimuthal index) in the wide frequency range of 75$115 \mathrm{GHz}$.
Analysing the MHC waveguide we have found out that the larger is the radius of the MHC waveguide, the greater number of modes is propagated in the MHC waveguide. We were assured of the correctness of this statement after we had made numerical computations. We have noted that the ratio of $h$ and $k$ values for the MHC waveguide is $h / k \leq 1$. Therefore all the modes of the MHC waveguide we have analysed are fast (the phase speed is larger than the light speed).

We have noted that when the value of the azimuthal index $m=2$, the main mode is parallel to the frequency axis. The MHC waveguide for the mode with indices $m=2$ and $n=1$ is nondispersional waveguide structure.

\section{References}

[1] H.-T. Chen, J.F. O’Hara, A.J. Taylor, R.D. Averitt, C. Highstrete, M. Lee, and W.J. Padilla, Complementary planar terahertz metamaterials, Opt. Express 15(3), 1084-1095 (2007).

[2] R. Ruppin, Surface polaritons of a left-handed medium, Phys. Lett. A 277(1), 61-64 (2000).

[3] R. Ruppin, Surface polaritons of a left-handed material slab, J. Phys. Cond. Matter 13(9), 1811-1819 (2001).

[4] G. Humbert, J. Knight, G. Bouwmans, P. Russell, D. Williams, P. Roberts, and B. Mangan, Hollow core photonic crystal fibers for beam delivery, Opt. Express 12(8), 1477-1484 (2004).

[5] D.G. Ouzounov, F.R. Ahmad, D. Muller, N. Venkataraman, M.T. Gallagher, M.G. Thomas, J. Silcox, K.W. Koch, and A.L. Gaeta, Generation of megawatt optical solitons in hollow-core photonic band-gap fibers, Science 301(5640), 1702-1704 (2003).

[6] J.D. Shephard, J.D.C. Jones, D.P. Hand, G. Bouwmans, J.C. Knight, P.St.J. Russell, and B.J. Mangan, High energy nanosecond laser pulses delivered single-mode through hollow-core PBG fibers, Opt. Express 12(4), 717-723 (2004).

[7] D.R. Smith, P. Rye, D.C. Vier, A.F. Starr, J.J. Mock, and T. Perram, Design and measurement of anisotropic metamaterials that exhibit negative refraction, IEICE Trans. Electron. E87-C(3), 359 (2004).

[8] K.Y. Kim, H.-S. Tae, and J.-H. Lee, Analysis of leaky modes in circular dielectric rod waveguides, Electron. Lett. 39(1), 61-62 (2003).

[9] R.S. Penciu, M. Kafesaki, T.F. Gundogdu, E.N. Economou, and C.M. Soukoulis, Theoretical study of left-handed behavior of composite metamaterials, Photonics Nanostruct. 4(1), 12-16 (2006). 


\title{
METAMEDŽIAGINIŲ TUŠČIAVIDURIŲ CILINDRINIU BANGOLAIDŽIŲ DISPERSINĖS CHARAKTERISTIKOS
}

\author{
L. Nickelson, T. Gric, S. Ašmontas
}

Puslaidininkiu fizikos institutas, Vilnius, Lietuva

\section{Santrauka}

Nagrinèjamas metamedžiaginis tuščiaviduris cilindrinis bangolaidis. Siekiant išnagrinèti tokių bangolaidžių savybes, spręstos Maksvelo lygtys. Gauta dispersinė lygtis buvo užrašyta determinanto pavidalu. Naudojant MATLAB programavimo kalbą, buvo sukurtas kompiuterinis algoritmas metamedžiaginių tuščiavidurių cilindrinių bangolaidžių dispersinėms savybėms analizuoti. Me- tamedžiaginis tuščiaviduris bangolaidis su skirtingais parametrais (skirtingas spindulys, azimutinis periodiškumo indeksas) buvo analizuojamas 75-115 GHz ruože. Ištirtos metamedžiaginio tuščiavidurio cilindrinio bangolaidžio pagrindinès bei aukščiausiosios eilès modų dispersinių charakteristikų priklausomybès nuo bangolaidžio spindulio ir azimutinio indekso. 